\title{
DETERMINATION OF ARSENIC CONCENTRATION IN GROUND WATER AND ITS EF- FECTS ON CHILDREN: A CASE STUDY OF SONARPUR AND BARUIPUR BLOCK, SOUTH 24 PARGANAS, WEST BENGAL
}

\author{
Paramita Chaudhuri, Pritam Aitch and Amit Dutta \\ Jadavpur University, Kolkata, (West Bengal) India \\ Email: paramita.es@gmail.com
}

\begin{abstract}
Arsenic contamination in groundwater has been termed as 'the largest mass poisoning in history' because of its detrimental effects on human population (Mori et al 2018). The Bengal Delta Plain (BDP) is the most arsenic contaminated region among the whole world where millions of people use arsenic contaminated water for drinking purposes (Bhattacharya et al, 2002). Children are more susceptible to arsenic than adult. Consumption of high arsenic contaminated water from the very first stage of life can develop arsenic related skin problems in early life. The effects of arsenic induced health diseases have multidimensional influences on the society. Apart from physical manifestation, socio economic impacts have been confronted by the sufferer such as economic instability due to loss of work, social disgrace, suicidal tendency and many other causes are related to these (Das and Roy, 2013). GIS platform was used for the study to prepare a hazard map considering the arsenic concentration of the village level drinking water sources and the geographical location as input. Baruipur and Sonarpur block of South 24 Parganas district, West Bengal, was considered for the study.
\end{abstract}

Key words: Arsenic, Groundwater, Water Contamination, GIS Mapping

\section{Introduction}

Arsenic contamination in groundwater has been termed as "the largest mass poisoning in history" because of its detrimental effects on human population (Mori et al 2018). According to USEPA (1996) arsenic is considered as a human carcinogen. Arsenic contamination in groundwater and the chronic toxicity developed by arsenic contaminated water consumption has been a widely documented recent issue globally and the most affected part is the Southeastern Asian countries. Arsenic is a metalloid mainly existed in insoluble state in rocks and minerals (Routh and Hjelmquist, 2011). When arsenic comes into contact with oxygen or other substances present in air, water or soil, becomes soluble to water and released into the environment. People are exposed to this element by breathing, drinking, eating or dermal contact. Water and food are the two factors by which arsenic enters into human body. The effects of arsenic on human health is dependent on the dose and the duration of arsenic exposure.

The "Bengal Delta Plain" (BDP) is the most arsenic contaminated region among the whole world where millions of people use that arsenic contaminated water for drinking purposes (Bhattacharya et al, 2002). In BDP arsenic concentration in groundwater goes beyond the stipulated limit of national drinking water standards $(10 \mu / \mathrm{L}$ or $0.01 \mathrm{mg} / \mathrm{L}$ and where no other alternative is accessible it is $50 \mu / \mathrm{L}$ or $0.05 \mathrm{mg} / \mathrm{L})(\mathrm{BIS}, 2012)$ and WHO Standard $(0.01 \mathrm{mg} / \mathrm{L}$ or $10 \mu / \mathrm{L})(\mathrm{WHO}, 2011)$. Drinking water beyond the permissible limit can initiate serious arsenic related health issues to human beings. The symptoms developed after 8-10 years of consumption of high level of arsenic, but it can take 3 years to develop if the arsenic concentration is very high (Singh and Ghosh, 2012). The population who have to start their begining of life in highly arsenic contaminated region, are definitely exposed to arsenic throughout their life. In West Bengal the child population of 0-6 years old is 11.59 percent of total population (Census,2011). According to the stages of life span 1 month to 2 years is termed as infancy and 2-6 years is early childhood. Proper nutrition and water is essential for healthy development of a child. Malnutrition causes physical and mental growth retardation. 
The children are exposed to arsenic by infant formula milk, juice and food made by arsenic contaminated water. Children exposed to arsenic may develop stomach irritation, skin colour changes, blood vessel damage, reduction in nerve function and IQ scores (ATSDR, 2007). Also early arsenic exposure can accelerate the mortality rate among juvenile population. The initial indications of arsenic poisoning starts from the change of skin pigmentation and hyper keratosis which becomes visible after 1 year of arsenic exposure in West Bengal (Guha Majumder, 2000). The early sign of skin cancer is generally observed as pigmentation changes, skin lesions and dark patches on skin (WHO, 2018). Total 212 skin cancer patients and 38 patients with internal cancer among 4865 cases of arsenicosis were reported from arsenic affected villages of West Bengal (Guha Mazumder and Dasgupta, 2011). The symptoms of arsenic poisoning differs between people, gender, population, geographical location of a region. The study is mainly focused on arsenic induced skin lesions as the lesions are the early sign of arsenic poisoning and the study was done in 0-6 years old child population. The objective of the study is to prepare a hazard level map of arsenic concentration and determine the approximate number of children who have the chances to develop skin lesions.

\section{MATERIALS AND METHODS}

\section{Study Area}

The study area is Baruipur and Sonarpur blocks located in South 24 Parganas district and the district is located in the southern part of West Bengal. The district is extended from Kolkata to the remote villages of Sundarbans near Bay of Bengal. The district has 5 subdivisions and Sonarpur and Baruipur comes under Baruipur subdivision. In Baruipur there are 138 villages under 19 gram panchayats and in Sonarpur the number is 72 inhabited villages under 11 gram panchayats. These two blocks are surrounded by Kolkata, Bhangar I and II, Canning I and II, Jaynagar I, Magrahat II, Bishnupur I and Thakurpukur Maheshtola.

Figure 01: Study area showing A) India with West Bengal B)West Bengal with South 24

Parganas and C) South 24 Parganas with Baruipur and Sonarpur blocks

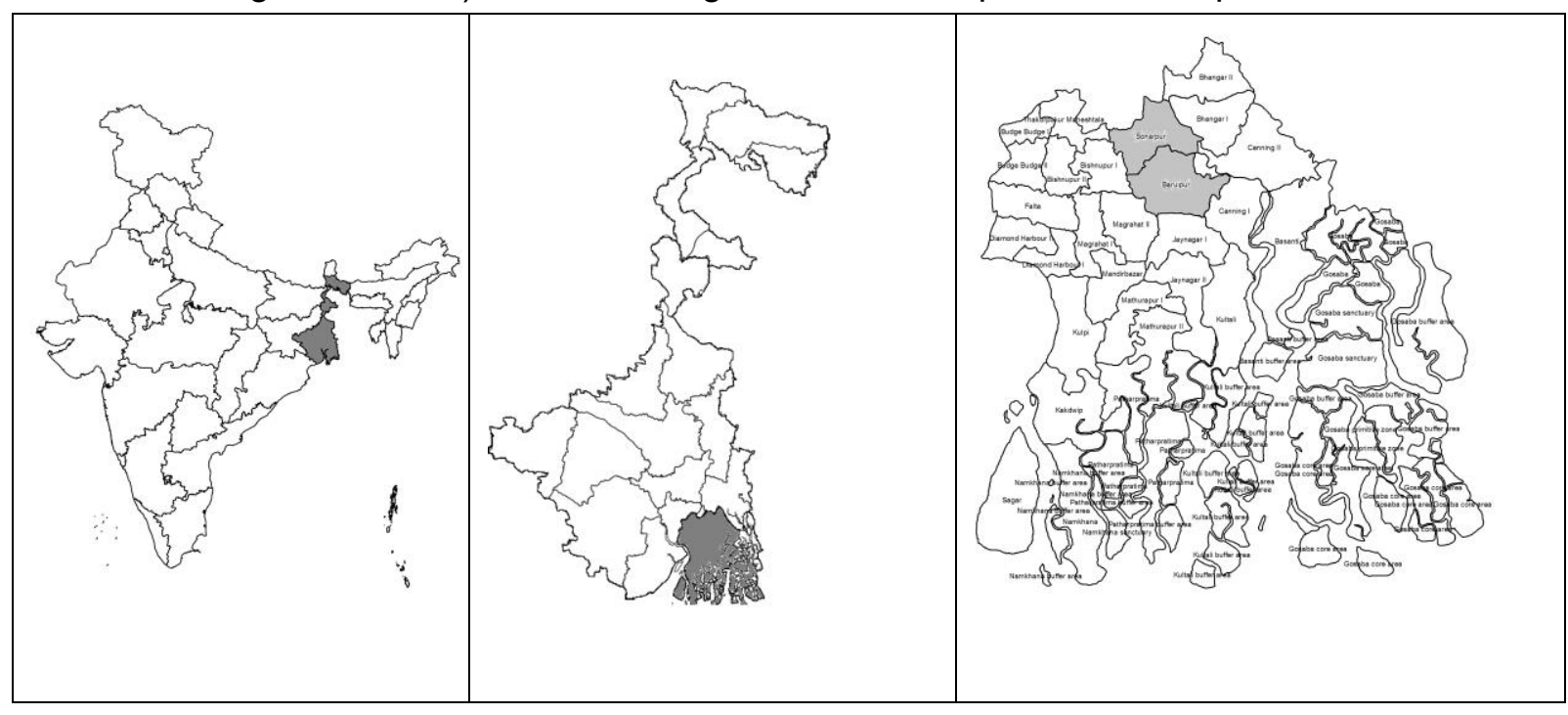

A

B

C

\section{Data Acquaintance}

Population distribution data was collected from Census data (2011) published by Census Commissioner, arsenic concentration in groundwater in tube well data was collected from portal of Public Health Engineering Department (2015). The statistical analysis was done using Microsoft Excel, 2010. All the maps were prepared by ArcGIS 10.2. For arsenic distribution map only arsenic affected blocks were taken and the highest As concentration of the villages were considered.

\section{Effects of Arsenic on Children}

Sonarpur and Baruipur have been categorized as highly arsenic affected region where $0.3 \mathrm{mg}$ $/ L$ of arsenic is found in many parts of the blocks (Chakraborti et al, 2009). An infant is 
exposed to arsenic when he or she starts taking formula milk or semisolid food made up by arsenic contaminated water. The exposure of arsenic in children is impacted by physiology and behavioural pattern. The symptoms of arsenic poisoning is more or less similar in child and adult population. Skin lesions are considered as the main diagnostic criteria for arsenicosis. Long term consumption of arsenic contaminated water can cause hyperkeratinization on palm and feet, keratinized warts, hyperpigmentation on skin and numbness in hands and feet. Squamous skin carcinoma is the most common skin cancer type which may be matured from keratinized warts (ATSDR, 2007).

\section{Hazard Assessment}

If the mean daily consumption of 0.0005 and $0.0008 \mathrm{mg} / \mathrm{L}$ arsenic contaminated water by $6-11$ months and 2 years old child, the effect is as equal as the mean daily consumption of 0.00051 $\mathrm{mg} / \mathrm{L}$ arsenic contaminated water consumed by a 25-30 years male. No dermal effects were reported by 0.0004 to $0.01 \mathrm{ppm}$ arsenic concentration. The increase of the prevalence of skin lesions was documented as if a person consumes $0.023 \mathrm{mg} / \mathrm{L}$ arsenic daily develop skin lesions. Skin lesions development is very much obvious if a person consume $0.1 \mathrm{mg} / \mathrm{L}$ arsenic contaminated water daily. (ATSDR, 2007).

\section{Skin Cancer Development}

The risk of cancer development due to ingestion of arsenic contaminated water was determined by the equation (Huy et al, 2014)

Tolerable daily intake (TDI) $=\mathrm{C} \times \frac{I R x E F x E D}{B W x A T}$

where $\mathrm{C}=$ arsenic concentration in drinking water $(\mathrm{mg} / \mathrm{L}), \mathrm{IR}=$ ingestion rate $(\mathrm{L} / \mathrm{day}), \mathrm{Ef}=$ exposure frequency (days/year of arsenic contaminated water used). ED= exposure duration (total years of ingestion of arsenic contaminated water), BW= body weight $(\mathrm{Kg})$ and $\mathrm{AT}=$ expectancy of life (day). The work was done with the age group 0 year to 6 years because exposure to arsenic in early life can increase the risk of arsenic induced effects in later part of life. In India expectancy of life is 68.5 years (World Bank,2018).

Risk characterization $=$ TDI $\times$ SF $\times$ ADAF

$\mathrm{SF}=$ slope factor for cancer development (only probability of skin cancer was considered due to the data accessibility) and ADAF= age dependent adjustment factor

\section{RESULT AND DISCUSSION}

\section{Distribution of Child Population among total Population in the Blocks}

Children are the main foundation of a nation and the progress of the nation is determined by the health of the children. There are 4 uninhabited villages in Baruipur. Most of the blocks in Baruipur contain 10-15 percent of child population, only a few have 15-20 percent child population.But in villages of Sonarpur the minimum percentage of population is 7 percent. A large portion of the block has population 8-10 percent and 10-15 percent among total population.

\section{Arsenic Distribution in the Blocks}

Baruipur and Sonarpur are the most arsenic contaminated blocks and arsenic concentration is very high in these two blocks. Arsenic concentration in tubewells were divided into 6 types. The first two divisions are the safe for drinking purposes and the rest four are above the permissible limit and unsafe for human consumption. In Baruipur 88 percent and Sonarpur almost 97 percent of tubewells contain water that are not harmful for human body according to WHO and BIS. Baruipur and Sonarpur contain arsenic concentration more than $1 \mathrm{mg} / \mathrm{L}$. In Baruipur the unsafe levels of arsenic is higher than Sonarpur. In Baruipur, the maximum concentration is 256 times and In Sonarpur it is 272 times greater than the WHO permissible limit. 
Table 01: Distribution of arsenic concentration in Baruipur and Sonarpur block

\begin{tabular}{|l|l|l|l|l|l|l|l|}
\hline \multirow{2}{*}{$\begin{array}{l}\text { Name of } \\
\text { the blocks }\end{array}$} & \multicolumn{5}{|c|}{ percent of tubewells having arsenic concentration in } & \multirow{2}{*}{$\begin{array}{c}\text { Maximum As } \\
\text { mg/L }\end{array}$} \\
\cline { 2 - 6 } & $\mathbf{0}$ & $\mathbf{0 . 0 1 - 0 . 0 5}$ & $\mathbf{0 . 0 6 - 0 . 1}$ & $\mathbf{0 . 1 1 - 0 . 5}$ & $\mathbf{0 . 5 1 - 1}$ & $\mathbf{1 . 1 - 3}$ & \\
\hline Baruipur & 80.78 & 7.34 & 2.18 & 8.35 & 1.17 & 0.15 & 2.56 \\
\hline Sonarpur & 48.9 & 47.73 & 1.29 & 0.38 & 0.25 & 0.12 & 2.72 \\
\hline
\end{tabular}

Figure 02: Percentage distribution of child population in Baruipur and Sonarpur block among the total population

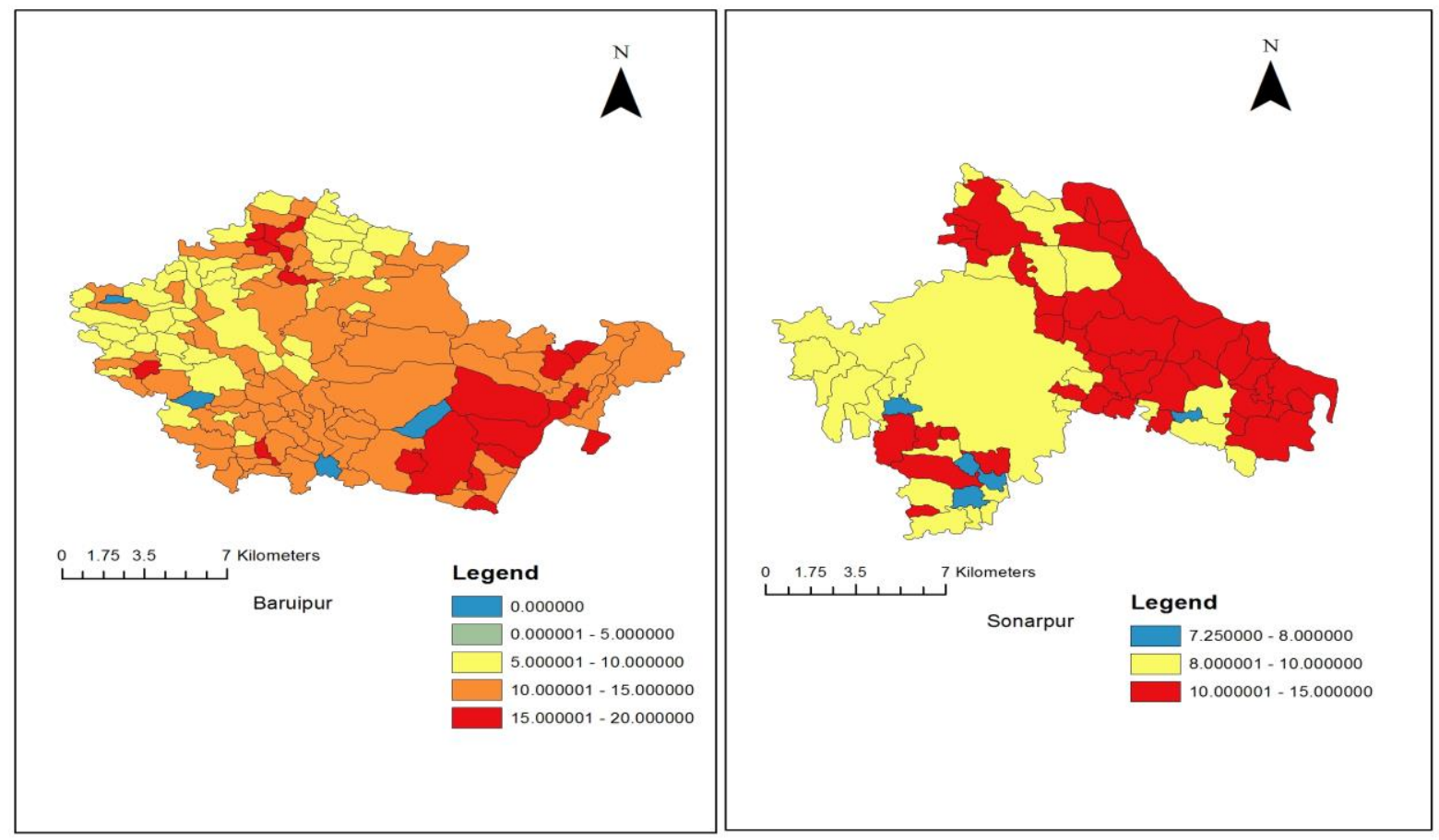

Figur 03: Arsenic distribution in Baruipur and Sonarpur blocks
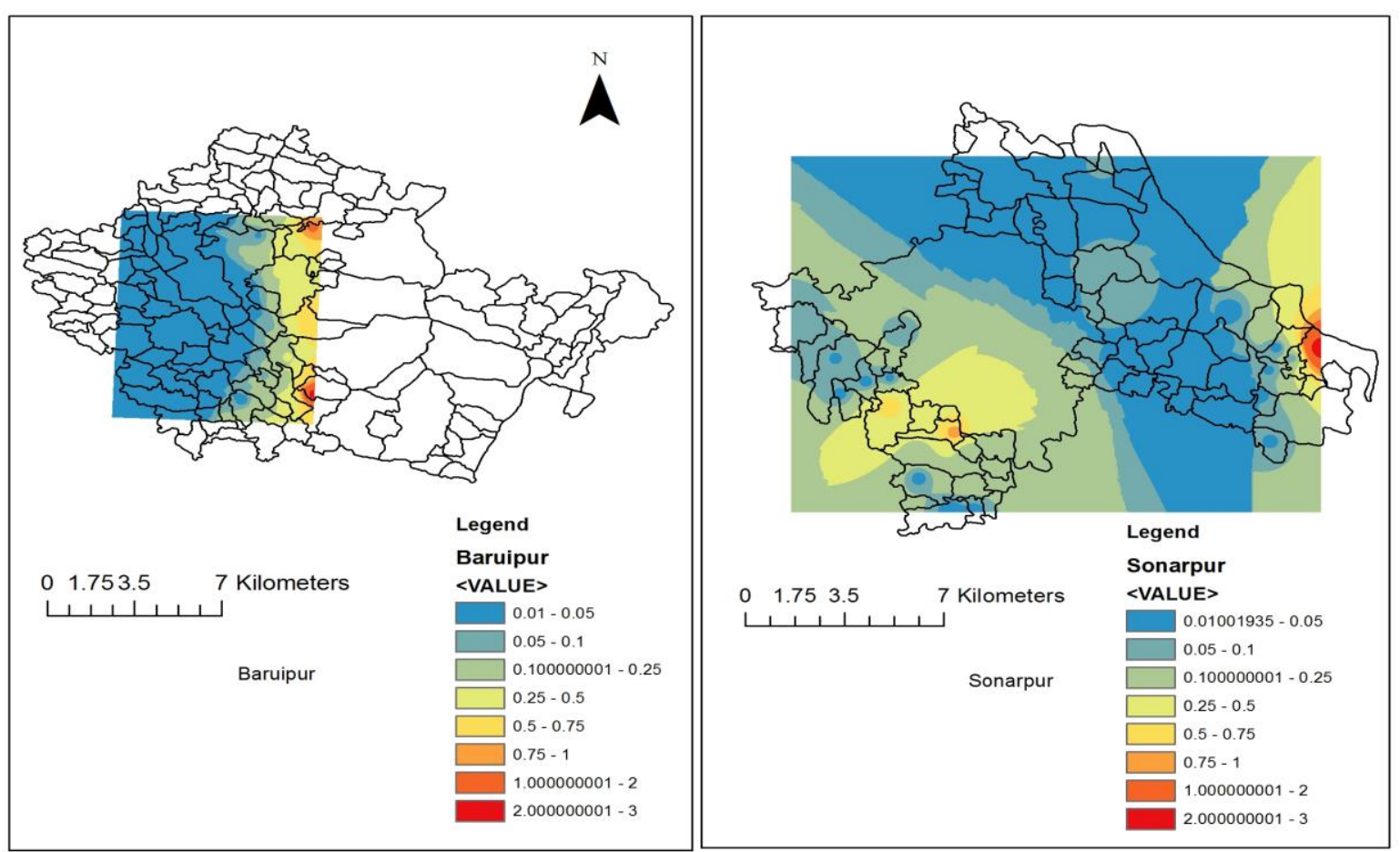
The white part signifies no arsenic zone. In Baruipur The villages in eastern and south eastern and western part of Baruipur are arsenic free. The western part has 0.01 to $0.05 \mathrm{mg} / \mathrm{L}$ concentration. The villages in Central part has arsenic concentration 0.1-0.25 mg/L, beside that a large stretch is contaminated with $0.25-0.5 \mathrm{mg} / \mathrm{L}$. A small pocket of concentration $2.5-3 \mathrm{mg} / \mathrm{L}$ and $1.5-2 \mathrm{mg} / \mathrm{L}$ are surrounded by $0.75-1 \mathrm{mg} / \mathrm{L}$. In Sonarpur, most of the part is contaminated by $0.01-0.05 \mathrm{mg} / \mathrm{L}$, according to BIS that is safe limit, only the north eastern and south western part have arsenic concentration $0.25-0.5 \mathrm{mg} / \mathrm{L}$. In the eastern part the region is mostly contaminated. The distribution of arsenic concentration is not even in the blocks. Arsenic is present in small patches. The maximum concentration is surrounded by lower arsenic concentration. The people who live in the arsenic patches are susceptible to arsenic poisoning.

\section{Hazard Assessment}

If a child consumes arsenic contaminated water more than permissible limit, the probable changes will occur on his/her skin (ATSDR, 2007)

Table 02: Skin lesion development with respect to Arsenic concentration

\begin{tabular}{|l|c|}
\hline As concentration $(\mathbf{m g} / \mathbf{L})$ & Skin lesion development \\
\hline $0-0.02$ & No skin lesion \\
\hline $0.03-0.09$ & prevalence to develop skin lesion \\
\hline $0.1-2.72$ & skin lesion is quite obvious \\
\hline
\end{tabular}

According to WHO (2011), $0.01 \mathrm{mg} / \mathrm{L}$ should be the maximum permissible limit for arsenic, but according to BIS (2012) it is $0.05 \mathrm{mg} / \mathrm{L}$ in India. But when a child starts drinking water with arsenic concentration 0.03- 0.09 there are chances to develop skin lesions. When the concentration is $0.1-2.72 \mathrm{mg} / \mathrm{L}$, skin lesion development is quite obvious. If two children lives in two different region and consume $0.1 \mathrm{mg} / \mathrm{L}$ and $2.72 \mathrm{mg} / \mathrm{L}$ arsenic contaminated water respectively, chances of skin lesion development is very high for the child who drinks $2.72 \mathrm{mg} / \mathrm{L}$ water regularly Chances of skin cancer development is directly proportional to increase of arsenic concentration. When the arsenic concentration is $0.4 \mathrm{mg} / \mathrm{L}$, there is chances to develop skin lesions in 240 children among 10000 children. When the concentration is more than $2.5 \mathrm{mg} / \mathrm{L}$, the chance is almost 1400 children among 10000. The villages have maximum arsenic concentration, have the chances to develop skin lesions more than other villages.

Figure 04: Relationship between Arsenic concentration (mg/L) and chances of skin cancer development in children

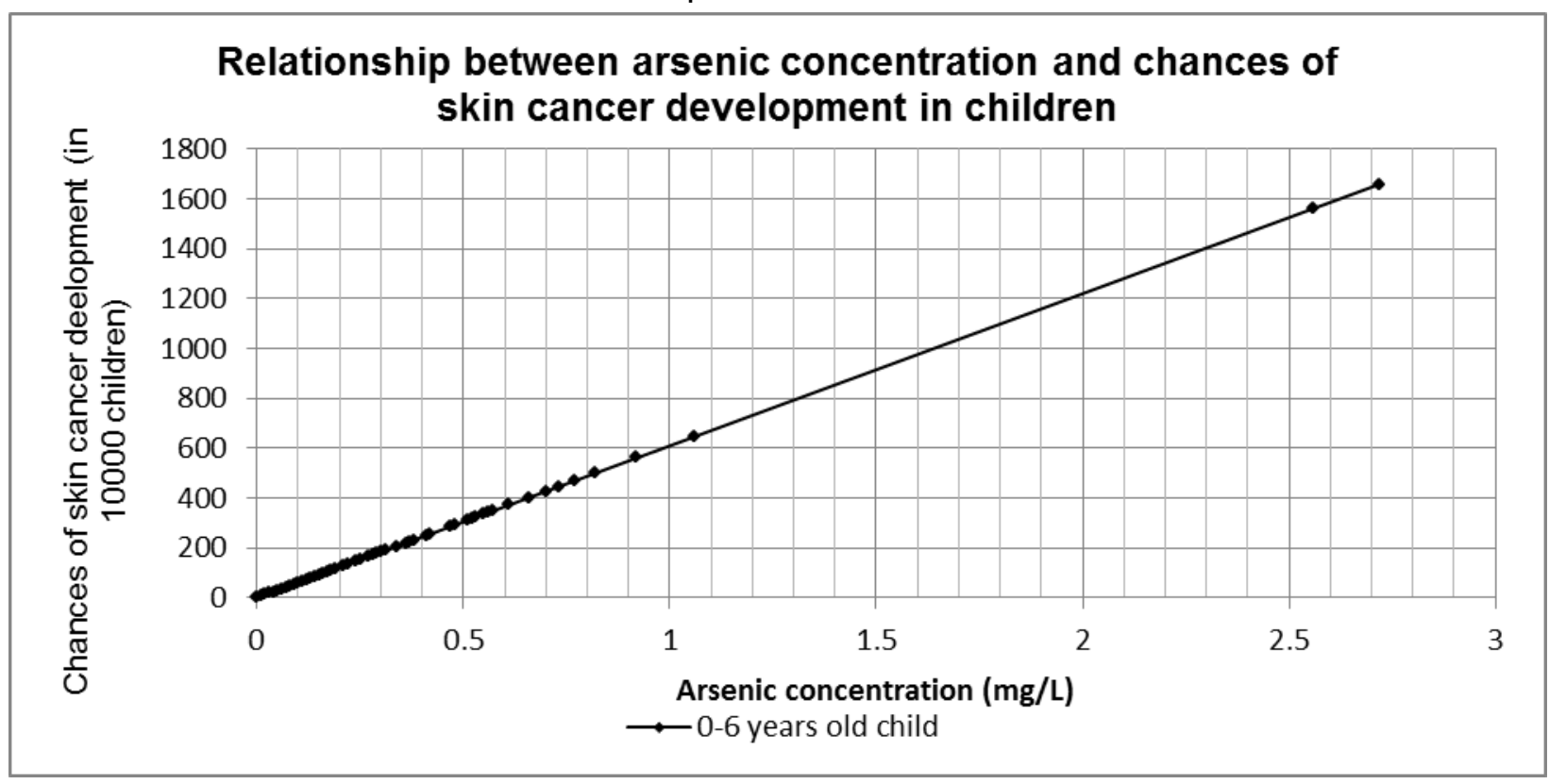


Figure 5: Child population affected by arsenic concentration in Baruipur and Sonarpur

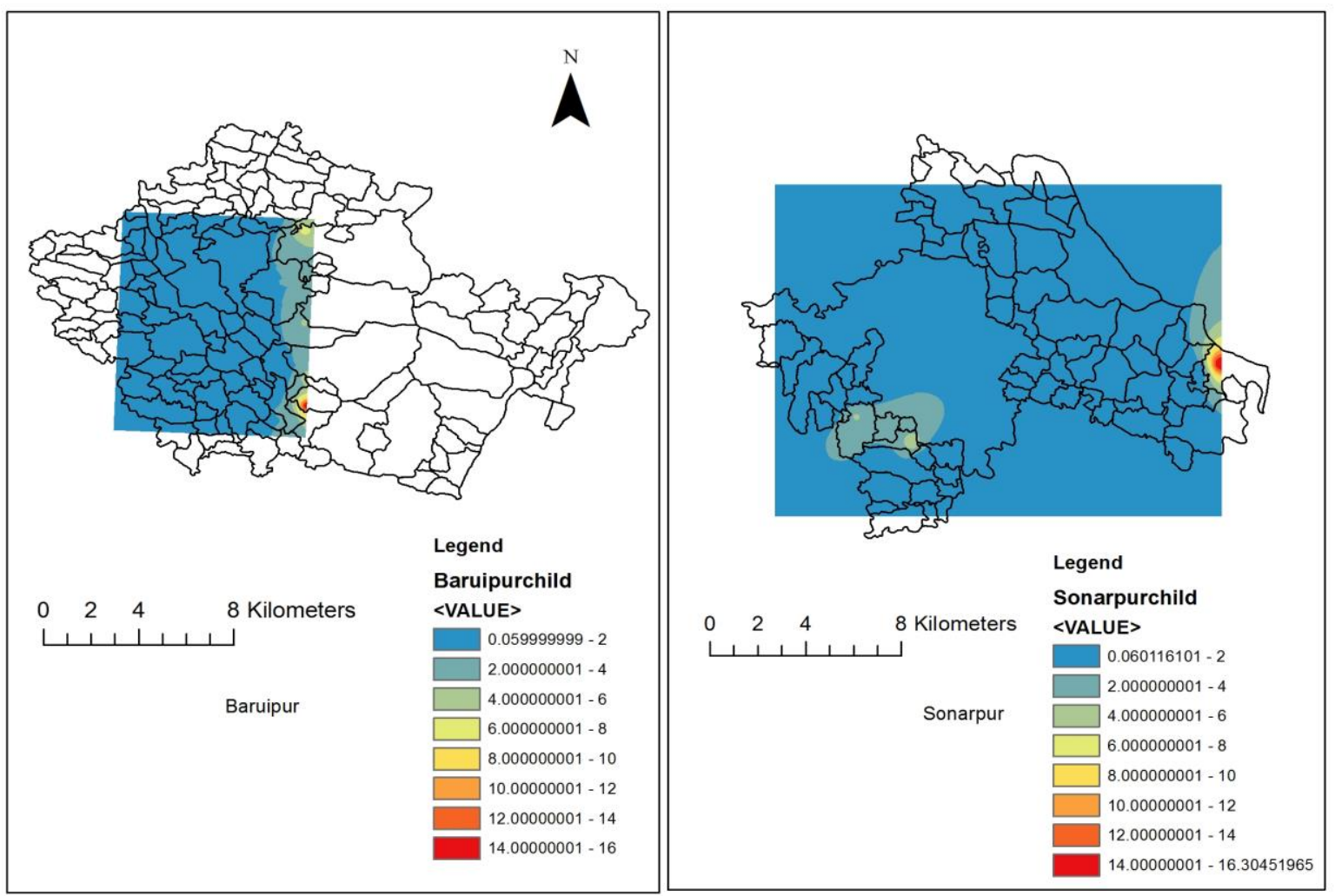

\section{Conclusion}

In Sonarpur the intensity of child population is little bit higher than Baruipur. Sonarpur is located near Kolkata. So, Sonarpur can be termed as peri-urban fringe where the urban cultures and influences cultivated with existing rural characteristics. The people comes from rural riverine villages of Sundarban to these semiurban areas and starts living. The parameters for the spatial growth are population growth, increase of family income and upgradation of transportation system (Patel and Teli, 2019). This population explosion cause the deterioration of the natural resources. The land resources are degraded, water becomes conatminated by toxic chemicals like arsenic. In Sonarpur, the most affected villages is Sangur $(2.72 \mathrm{mg} / \mathrm{L})$ in Pratapnagar Gram Panchayat and in Baruipur, Surjapur $(1.06 \mathrm{mg} / \mathrm{L})$ in Dhaapdhapi I and Paschim Mallikpur (2.56 mg/L) in Dhapdhapi II Gram Panchayat are the two most affected villages.

The infancy period is the most vital stage of a child's life as most of the growth and development takes place at this place. Nutritional status is the primary indicator of growth of a child. The effects of arsenic mainly depends on age and gender, nutritional status, water consumption pattern of a child. The child who is going through the arsenic poisoning symptoms, lives in the below poverty level and do not have the provision for safe water and good food. A malnourished child is much prone to develop arsenic induced skin disease. Malnutrition can also delays physical and mental development, lower response against immunity and susceptible to infection. The children, who have to consume high concentration of arsenic contaminated water from childhood, are susceptible to develop skin cancer at an early age. The effects of arsenic induced health diseases have multidimensional influences on the society. Apart from physical manifestation, socio economic impacts have been confronted by the sufferer such as economic instability due to loss of work, social disgrace, suicidal tendency and many other causes are related to these (Das and Roy, 2013). An alternative source of water for drinking and cooking purposes that is free from arsenic can reduce the risk of skin cancer development. Alternative sources may be rain water harvesting or other conventional methods of water conservation (Kumar and Mandar, 2018) 


\section{Reference}

1. Agency for Toxic Substances and Disease Registry (ATSDR) (2007) Report on 'Toxicological profile for Arsenic' published by U.S. Department of Health and Human Services, Public Health Services, Washington, DC, USA. https://www.atsdr.cdc.gov/toxprofiles/tp2.pdf, accessed on 12.09.2019

2. Bhattacharya, P., Jacks, G., Frisbie, S.H., Smith, E., Naidu, R. and Sarkar, B. (2002) 'Arsenic in the environment: a global perspective'. In: Sarkar, B. (Ed.), Heavy Metals in the Environment. Marcel Dekker, New York, pp. 47-215.

3. Bureau of Indian Standards (2012) Indian Standard Drinking water- Specification, http://cgwb.gov.in/Documents/WQ-standards.pdf, accessed on 10.09.2019

4. Census data of India (2011) http://censusindia.gov.in/2011census/dchb/ 1917_PART B_DCHB_SOUTH\%20TWENTY\%20FOUR\%20PARGANAS.pdf, accessed on 18.09.2019

5. Chakraborti, D., Das, B., Rahman, M.M., Chowdhury, U.K., Biswas, B., Goswami, A.B., Nayak, B., Pal, A., Sengupta, M.K., Ahamed, S., Hossain, A., Basu, G., Roychowdhury, T. and Das, D. (2009) 'Status of groundwater arsenic contamination in the state of West Bengal, India: A 20-year study report'. Molecular Nutrition and Food Research, 53 (5), pp. 542 $-551$

6. Chaudhuri, P., Aitch, P. and Dutta, A. (2019) 'Identification of Arsenic Hazard Locations and Impact on Children- A Case Study on Baruipur Block, South 24 Parganas, West Bengal' in Pal, I., Meding, J.V., Shrestha, S. and Gajendran, T. (ed.), An Interdisciplinary Approach for Disaster Resilience and Sustainability, Springer Nature, Singapore, pp. 427-450

7. Das, A. and Roy, R. (2013) 'Socio-Economic Fallout of Arsenicosis in West Bengal: A Case Study in Murshidabad District', Journal of the Indian Society of Agricultural Statistics 67(2), pp. $273-285$

8. Guha Majumder, D.N. (2000) 'Diagnosis and treatment of chronic arsenic poisoning,' in United Nations Synthesis Report on Arsenic in Drinking Water, WHO, Geneva, Switzerland.

9. Guha Mazumder, D.N. and Dasgupta, U.B. (2011). 'Chronic arsenic toxicity: Studies in West Bengal, India', Kaohsiung Journal of Medical Sciences 27, pp. 360-370

10. Huy, T.B., Tuyet-Hanh, T.T., Johnston, R. and Nguyen-Viet, H. (2014) 'Assessing Health Risk due to Exposure to Arsenic in Drinking Water in Hanam Province, Vietnam', International Journal of Environmental Research and Public Health, 11(8), pp. 75757591.

11. Kumar, R. and Mandar, B. (2018) 'GIS based study on groundwater quality of Sikar district, Rajasthan', Journal of Global Resources, 4 (01), pp. 81-88

12. Mori, S., Lowenstein, E.J. and Steffen, C. (2018). 'The Largest Mass Poisoning in History: Arsenic Contamination of Well Water in Bangladesh', SKINmed 16(4): pp. 265-267

13. Patel, U.B. and Teli , B. L. (2019) 'Population and urban sprawl in Lucknow city: problems \& prospects', Journal of Global Resources, 5 (01), pp 01-12

14. PHED Portal (2015) Public Health Engineering Department, Accessed on 25.3.2017

15. Routh, J. and Hjelmquist, P. (2011) 'Distribution of arsenic and its mobility in shallow aquifer sediments from Ambikanagar, West Bengal, India', Applied Geochemistry 26, pp. 505-515.

16. Singh, S.K. and Ghosh, A.K. (2012) 'Health Risk Assessment Due to Groundwater Arsenic Contamination: Children Are at High Risk', Human and Ecological Risk Assessment, 18 (4), pp. 751-766

17. USEPA (U.S. Environmental Protection Agency) (1996) Proposed guidelines for carcinogen risk assessment. Notice, Federal Register 61(79):17959-18011, https://cfpub.epa. gov/ncea/raf/pdfs/propcra_1996.pdf, accessed on 19.9.2019

18. World Health Organization (2011) Guidelines for Drinking water Quality, 4, pp 315

19. World Health Organization (2018). https://www.who.int/news-room/fact-sheets/detail/ arsenic. Accessed on 19.09.2019

20. www.who.int/news-room/fact-sheets/detail/arsenic,2018 accessed on 25.06.2019 